\title{
Eosinophilic meningitis following suboccipital craniotomy without bovine dural graft: illustrative case
}

\author{
Woo Cheul Cho, MD, Hyeong Jin Lee, MD, Jung Koo Lee, MD, and Jai Ho Choi, MD, PhD \\ Department of Neurosurgery, Seoul St. Mary's Hospital, The Catholic University of Korea College of Medicine, Seoul, South Korea
}

BACKGROUND Eosinophilic meningitis is a rare known complication after brain surgery associated with duraplasty using artificial bovine graft. However, eosinophilic meningitis after craniotomy without bovine dural graft has not been reported.

OBSERVATIONS A 48-year-old female presented with lateral medullary infarction caused by a vertebral artery dissecting aneurysm incorporating the posterior inferior cerebellar artery (PICA). The authors performed occipital artery-PICA anastomosis and repaired the dura by primary suture without bovine graft. Thereafter, endovascular internal trapping using coils was conducted. Severe headache developed at postoperative day 17 , and the patient was diagnosed with eosinophilic meningitis. After administration of a high-dose corticosteroid for 2 weeks, her symptoms and laboratory findings were improved.

LESSONS Postoperative eosinophilic meningitis is rarely related to craniotomy without using bovine graft. Neurosurgeons should consider the possibility of eosinophilic meningitis after craniotomy without a xenogeneic dural material.

https://thejns.org/doi/abs/10.3171/CASE21603

KEYWORDS eosinophilic meningitis; duraplasty; bovine graft; corticosteroid

Parasitic infection is the most common cause of eosinophilic meningitis. However, other causes, such as other infectious processes, neoplasm, and foreign body implantation during neurosurgical procedures, have also been reported. Previous reports have described the occurrence of eosinophilic meningitis after duraplasty using a bovine dural graft. Here, the authors report a patient who presented with eosinophilic meningitis with hydrocephalus after suboccipital craniotomy without a bovine dural graft for occipital artery-posterior inferior cerebellar artery (OA-PICA) anastomosis.

\section{Illustrative Case}

\section{History and Clinical Course}

A 48-year-old female presented with dizziness, falling tendency to the right side, and left-sided hypesthesia for 2 weeks. She was diagnosed with right medullary infarction caused by a vertebral artery dissecting aneurysm (VADA) incorporating the PICA on magnetic resonance imaging (MRI) and magnetic resonance angiography (MRA). After medical management of medullary infarction, all symptoms disappeared without any neurological deficits. However, severe headache and posterior neck pain developed about 2 weeks later, and the symptoms persisted for 6 months. Follow-up MRA showed interval progression with size increase of the previously noted VADA. Because the PICA was incorporated in the VADA, OA-PICA anastomosis with midline suboccipital craniotomy was performed to prevent PICA territory infarction before endovascular internal trapping. The dura mater was repaired with a primary suture augmented with fibrin sealant (TachoSil). Thereafter, internal trapping with detachable coils was performed. The patient was discharged at 7 days after surgery without any periprocedural complications.

Ten days after discharge, the patient visited the emergency department due to aggravation of headache, nausea, vomiting and wound swelling with cerebrospinal fluid (CSF) leakage. There were no findings suggestive of infection, including laboratory results of a normal white blood cell count and C-reactive protein value. CSF analysis revealed a corrected white blood cell count of 1,782 cells/ $\mu \mathrm{L}$ with $20 \%$ eosinophils,

ABBREVIATIONS CSF = cerebrospinal fluid; MRA = magnetic resonance angiography; MRI = magnetic resonance imaging; OA = occipital artery; PGLA = polyglycolic lactic acid; PICA = posterior inferior cerebellar artery; VADA = vertebral artery dissecting aneurysm.

INCLUDE WHEN CITING Published January 10, 2022; DOI: 10.3171/CASE21603.

SUBMITTED October 20, 2021. ACCEPTED November 29, 2021.

(c) 2022 The authors, CC BY-NC-ND 4.0 (http://creativecommons.org/licenses/by-nc-nd/4.0/). 


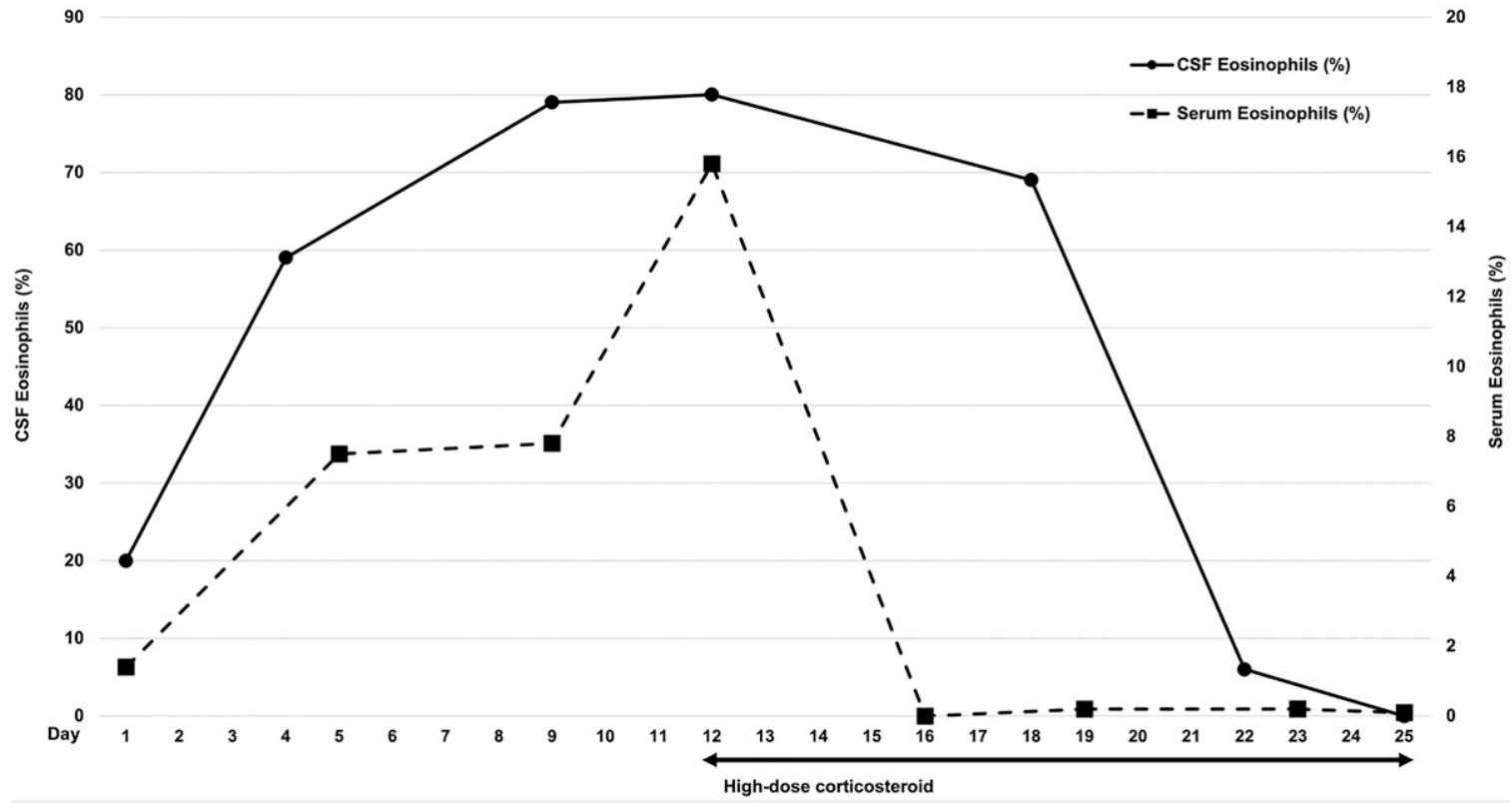

FIG. 1. Graph of changes in the percentage of eosinophils in the CSF and serum. High-dose corticosteroids were administered for 2 weeks after the 12 th day of hospitalization.

$17 \%$ neutrophils, and $61 \%$ lymphocytes; protein level of $499 \mathrm{mg} / \mathrm{dL}$; and glucose level of $13 \mathrm{mg} / \mathrm{dL}$. An MRI of the brain with contrast revealed postoperative fluid collection with subtle peripheral rim enhancement and without diffusion restriction. Microorganisms were not identified in CSF and blood cultures. Also, results of a micro-enzyme-linked immunosorbent assay for parasitic infection and multiple-antigen simultaneous test for allergic reaction were negative.

\section{Treatment and Post-treatment Course}

The patient was initially administered empirical intravenous antibiotics, including vancomycin and ceftriaxone, after initial CSF sampling. Despite empirical antibiotic therapy for 2 weeks, the patient's symptoms did not improve, and her CSF eosinophil count gradually increased. Therefore, we started a high dose of oral prednisolone (60 $\mathrm{mg} /$ day) because we thought that her symptoms were caused by eosinophilic meningitis. Three days after corticosteroid treatment, her clinical symptoms, including severe headache, dizziness, nausea, and vomiting, were totally resolved. Her CSF and serum eosinophil counts were also normalized after treatment (Fig. 1).

Although the clinical symptoms improved, wound swelling and hydrocephalus were aggravated. Consequently, the patient underwent ventriculoperitoneal shunting with repair surgery for CSF leakage. The pathologic findings of dural tissue obtained during the surgery showed a few eosinophilic infiltrations with foreign body reaction (Fig. 2). After shunt with dura repair, the patient was discharged without any complications.

\section{Discussion}

\section{Observations}

To our knowledge, this is the first case of eosinophilic meningitis after craniotomy without using an artificial bovine dural graft. The diagnosis of eosinophilic meningitis is based on clinical manifestations and the presence of eosinophils in the CSF. The definition of eosinophilic meningitis is as follows: (1) the presence of 10 or more eosinophils in the CSF per microliter or (2) eosinophilia not $<10 \%$ of the total CSF leukocyte count. ${ }^{1}$ Eosinophilic meningitis is commonly associated with parasitic infection, and other infectious conditions and noninfectious causes have also been related to eosinophilic meningitis. ${ }^{1-4}$ Although postoperative eosinophilic meningitis is a very rare complication, several previous studies have reported that a hypersensitivity reaction with foreign materials can lead to postoperative eosinophilic meningitis. One previous report described that eosinophilic meningitis occurred after duraplasty using a bovine dural graft following spinal cord untethering. The patient fully recovered after surgical removal of the grafted bovine substitute. ${ }^{5}$ Another case report has been published of a patient who presented with eosinophilic meningitis after a bovine dural graft for Chiari malformation type I repair and was treated with corticosteroid therapy. ${ }^{6}$ However, our patient underwent dural closure with a simple suture without using any bovine material.

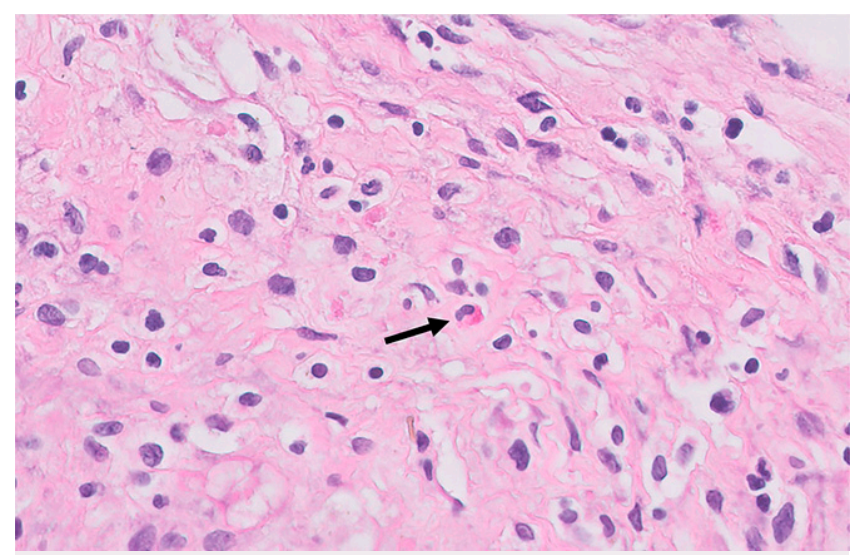

FIG. 2. H\&E stain (original magnification $\times 400$ ) of dural tissue from CSF repair surgery showing eosinophilic infiltration (arrow). 
TABLE 1. Comparison of CSF findings and characteristics among postoperative eosinophilic, chemical/aseptic, and bacterial meningitis

\begin{tabular}{|c|c|c|c|}
\hline Variable & Eosinophilic Meningitis & Chemical/Aseptic Meningitis & Bacterial Meningitis \\
\hline CSF eosinophils (\%) & $>10 \%$ & NA & NA \\
\hline CSF protein $(\mathrm{mg} / \mathrm{mL})$, mean (IQR) & Slightly increased & $100(55-215)$ & $115(62-258)$ \\
\hline CSF culture & Negative & Negative & Positive \\
\hline Fever $\left(>38^{\circ} \mathrm{C}\right)$ & $\sim 10 \%$ & $63 \%$ & $76 \%$ \\
\hline Neck stiffness & $46 \%$ & $33 \%$ & $24 \%$ \\
\hline Causes & $\begin{array}{c}\text { Parasite } \\
\text { Artificial material } \\
\text { Drug } \\
\text { Malignancy }\end{array}$ & $\begin{array}{c}\text { Viral infection } \\
\text { Blood breakdown products }\end{array}$ & Surgical wound infection \\
\hline
\end{tabular}

$\mathrm{IQR}=$ interquartile range; $\mathrm{NA}=$ not available.

Aseptic meningitis is the most common cause of postoperative meningitis. A previous paper demonstrated that aseptic meningitis occupied approximately $60-75 \%$ of postoperative meningitis. ${ }^{7}$ Including headache, vomiting, and fever, the clinical manifestation of aseptic meningitis is similar to that of eosinophilic meningitis. However, the CSF eosinophilia is not accompanied by CSF analysis in cases of aseptic meningitis. Both aseptic and eosinophilic meningitis show a negative result of CSF culture, which is distinguished from bacterial meningitis. In addition, CSF components were affected by the surgical procedure itself, and we have compared postoperative aseptic, bacterial, and eosinophilic meningitis. Table 1 summarizes CSF laboratory findings, symptoms, possible causes, and treatments among these three meningitides. 8,9

In this case, we used fibrin sealants (Tisseel and TachoSil) to avoid CSF leakage. Safety and adverse effects of fibrin sealants have been described in a previous meta-analysis. Three cases of aseptic meningitis and two cases of allergic reaction were demonstrated in that study. ${ }^{10}$ Tisseel is commonly used in neurosurgery to prevent CSF leakage, and it consists of human fibrinogen, aprotinin, thrombin, and calcium chloride. Among the components, aprotinin is a protein known to be associated with anaphylactic reaction. ${ }^{11}$ One case report showed that anaphylactic shock occurred after fibrin sealant (Tissucol) injection for cranial surgery for metastasis. ${ }^{12}$ Another case report described an allergic reaction after arachnoid plasty with a fibrin sealant (Beriplast) for unruptured intracranial aneurysm neck clipping. ${ }^{13}$ TachoSil is a biological sealant matrix consisting of human thrombin and fibrinogen. Some authors have reported postsurgical meningitis after using TachoSil. ${ }^{14,15}$ However, these cases were not diagnosed with eosinophilic meningitis, different from our study. In addition, the association between eosinophilic meningitis and fibrin sealants has not been reported. ${ }^{10,14,15}$

Because our patient underwent internal trapping with detachable coils for a VADA, we thought that coils might be associated with eosinophilic meningitis. Coil-associated aseptic meningitis and perianeurysmal edema have been reported previously. ${ }^{16-19}$ Some authors have suggested that the concurrent use of polyglycolic lactic acid (PGLA)-coated coil and hydrogel-coated coil may cause chemical meningitis. ${ }^{17}$ Three cases of aseptic meningitis after the use of hydrogel-coated coil have been reported. ${ }^{16}$ Another case report suggested that an inflammatory reaction to a PGLA-coated coil can induce perianeurysmal edema after coil embolization. ${ }^{19}$ However, both PGLA and bioactive hydrogel-coated coils were not used in this study. Moreover, there was no report that revealed the relationship between eosinophilic meningitis and detachable coils.

Corticosteroids have been suggested as the main treatment modality for eosinophilic meningitis in previous studies. ${ }^{20-22}$ Chotmongkol et al. recommended a high dose (60 mg/day) of oral prednisolone for 2 weeks to treat eosinophilic meningitis. ${ }^{20}$ Sawanyawisuth et al. reported that the symptoms of eosinophilic meningitis in 47 of 52 patients subsided after administration of a high-dose steroid regimen for 1 week. $^{21}$ Our patient was also treated with $60 \mathrm{mg} /$ day of oral prednisolone for 2 weeks. Similar to the previous study, the symptoms of our patient disappeared, and CSF eosinophilia normalized.

\section{Lessons}

We report the first case of postoperative eosinophilic meningitis after craniotomy without using a bovine dural graft, although the etiology was not clearly identified. Even though this might be an extremely rare case, surgeons should consider the possibility of eosinophilic meningitis after craniotomy without a xenogeneic dural material. Early detection and appropriate use of high-dose steroid for 2 weeks might be important to manage eosinophilic meningitis after craniotomy.

\section{References}

1. Lo Re V 3rd, Gluckman SJ. Eosinophilic meningitis. Am J Med. 2003;114(3):217-223.

2. Bezerra S, Frigeri TM, Severo CM, Santana JC, Graeff-Teixeira C. Cerebrospinal fluid eosinophilia associated with intraventricular shunts. Clin Neurol Neurosurg. 2011;113(5):345-349. 
3. Federspiel F, Skovmand S, Skarphedinsson S. Eosinophilic meningitis due to Angiostrongylus cantonensis in Europe. Int J Infect Dis. 2020; 93:28-39.

4. Graeff-Teixeira C, da Silva AC, Yoshimura K. Update on eosinophilic meningoencephalitis and its clinical relevance. Clin Microbiol Rev. 2009;22(2):322-348.

5. Foy $A B$, Giannini $C$, Raffel $C$. Allergic reaction to a bovine dural substitute following spinal cord untethering. Case report. J Neurosurg Pediatr. 2008;1(2):167-169.

6. Ostendorf AP, Connolly AM. Medical management of eosinophilic meningitis following bovine graft duraplasty for Chiari malformation type I repair: case report. J Neurosurg Pediatr. 2013;12(4):357-359.

7. Zarrouk V, Vassor I, Bert F, et al. Evaluation of the management of postoperative aseptic meningitis. Clin Infect Dis. 2007;44(12): 1555-1559.

8. Wang QP, Lai DH, Zhu XQ, Chen XG, Lun ZR. Human angiostrongyliasis. Lancet Infect Dis. 2008;8(10):621-630.

9. Choi SH, Choi SH. Predictive performance of serum procalcitonin for the diagnosis of bacterial meningitis after neurosurgery. Infect Chemother. 2013;45(3):308-314.

10. Esposito F, Angileri FF, Kruse $P$, et al. Fibrin sealants in dura sealing: a systematic literature review. PLoS One. 2016;11(4):e0151533.

11. Dietrich W, Ebell A, Busley R, Boulesteix AL. Aprotinin and anaphylaxis: analysis of 12,403 exposures to aprotinin in cardiac surgery. Ann Thorac Surg. 2007;84(4):1144-1150.

12. Beierlein W, Scheule AM, Antoniadis G, Braun C, Schosser R. An immediate, allergic skin reaction to aprotinin after reexposure to fibrin sealant. Transfusion. 2000;40(3):302-305.

13. Kanazawa R, Sato S, Iwamoto N, Teramoto A. Allergic reaction following arachnoid plasty with a fibrin sealant. Neurol Med Chir (Tokyo). 2010;50(7):608-610.

14. Hutter G, von Felten S, Sailer MH, Schulz M, Mariani L. Risk factors for postoperative CSF leakage after elective craniotomy and the efficacy of fleece-bound tissue sealing against dural suturing alone: a randomized controlled trial. J Neurosurg. 2014;121(3): 735-744.

15. Qiu L, Qi See AA, Steele TWJ, Kam King NK. Bioadhesives in neurosurgery: a review. J Neurosurg. 2019;133:1928-1938.

16. Im SH, Han MH, Kwon BJ, Jung C, Kim JE, Han DH. Aseptic meningitis after embolization of cerebral aneurysms using hydrogel- coated coils: report of three cases. AJNR Am J Neuroradiol. 2007;28(3):511-512.

17. Meyers PM, Lavine SD, Fitzsimmons BF, et al. Chemical meningitis after cerebral aneurysm treatment using two second-generation aneurysm coils: report of two cases. Neurosurgery. 2004;55(5): E1222-E1227.

18. Park JH, Kang HS, Han MH, Jeon P, Yoo DS, Lee TH. Embolization of intracranial aneurysms with HydroSoft coils: results of the Korean multicenter study. AJNR Am J Neuroradiol. 2011;32(9):1756-1761.

19. Stracke CP, Krings T, Möller-Hartmann W, Mahdavi A, Klug N. Severe inflammatory reaction of the optic system after endovascular treatment of a supraophthalmic aneurysm with bioactive coils. AJNR Am J Neuroradiol. 2007;28(7):1401-1402.

20. Chotmongkol V, Sawanyawisuth K, Thavornpitak Y. Corticosteroid treatment of eosinophilic meningitis. Clin Infect Dis. 2000;31(3): 660-662.

21. Sawanyawisuth $K$, Limpawattana $P$, Busaracome $P$, et al. A 1-week course of corticosteroids in the treatment of eosinophilic meningitis. Am J Med. 2004;117(10):802-803.

22. Thanaviratananich $S$, Thanaviratananich $S$, Ngamjarus C. Corticosteroids for parasitic eosinophilic meningitis. Cochrane Database Syst Rev. 2015;(2):CD009088.

\section{Disclosures}

The authors report no conflict of interest concerning the materials or methods used in this study or the findings specified in this paper.

\section{Author Contributions}

Conception and design: Choi, Cho. Acquisition of data: Choi, Cho. Analysis and interpretation of data: Choi, Cho. Drafting the article: Cho, HJ Lee. Critically revising the article: Choi, Cho, HJ Lee. Reviewed submitted version of manuscript: Choi, Cho, JK Lee. Approved the final version of the manuscript on behalf of all authors: Choi. Administrative/ technical/material support: Choi. Study supervision: Choi.

\section{Correspondence}

Jai Ho Choi: Seoul St. Mary's Hospital, The Catholic University of Korea College of Medicine, Seoul, South Korea. bivalvia@catholic.ac.kr. 